\title{
Orthodontically Induced Microvascular Injuries in the Tension Zone of the Periodontal Ligament
}

\author{
Kenneth K. K. LEW, BDS, MDS \\ (Received 8 May and accepted 9 May 1989)
}

Key words: orthodontic movement, periodontal microvasculature, blood supply, postcapillary venules, capillary type

\begin{abstract}
A review of the literature pertaining to the histological and ultrastructural changes related to orthodontic tooth movement reveals that much attention has been devoted to the fibrillar and cellular components of the periodontal ligament (PDL). Although the vascular response to experimental tooth movement has been investigated, specific morphological and morphometric data on changes in the tension zone of the PDL microvascular system are lacking. The present investigation was conducted to study the ultrastructural vascular response in the tension zone of the PDL following a short-term extrusive force. Six 12-week-old male Porton rats were anesthetized and cannulated via the aorta after applying a $1-\mathrm{N}$ extrusive force for $30 \mathrm{~min}$ to the right maxillary first molar. The contralateral molar served as a control in all animals. The apical portion of both the control and experimental PDL was prepared for TEM examination. In the experimental PDL, degenerative changes in the endothelial cell wall and incipient nuclear shrinkage were observed in about $30 \%$ of the postcapillary venules and $18 \%$ of the capillaries, whereas the arterial components were generally spared. Compared to the control PDL, these degenerative changes were significantly marked in the experimental PDL $(p<0.01)$. The results of this study suggest that the postcapillary venules are the most vulnerable segment in the PDL microvascular system.
\end{abstract}

\section{Introduction}

The sequential vascular changes in the pressure zone of the PDL appear to be well documented. Early changes include stasis ${ }^{[1]}$ and ischemia of blood vessels ${ }^{[2-4]}$. These early changes are followed by a gradual decrease in the number of patent capillaries $^{[5,6]}$, thrombosis ${ }^{[4,7]}$, complete obliteration of the blood vessels ${ }^{[7,8]}$ and vascular degeneration ${ }^{[1,9]}$. Regeneration and proliferation of the blood vessels within the pressure zone usually predominate after 7 days ${ }^{[1,10,11]}$.

In comparison, descriptions of microvascular changes in the tension zone of the PDL appear to be scarce in the literature. The only vascular changes that have been documented in the tension zone are dilation and distension of blood vessels in the direction of the $\operatorname{strain}^{[10-12]}$. 
The rat molar has been used extensively as a model for vascular changes associated with tooth movement (Table 1). While most authors have concentrated

Table 1 A synopsis of studies documenting vascular changes observed in rat molars following force application

\begin{tabular}{|c|c|c|c|c|}
\hline STUDY & FORCE $(\mathrm{N})$ & DURATION & COMPRESSION & TENSION \\
\hline $\begin{array}{l}\text { Macapanpan et al. } \\
(1954)^{[5]}\end{array}$ & $?$ & $1 \mathrm{~h}$ & $\begin{array}{l}\text { Empty capillaries, normal } \\
\text { width }\end{array}$ & $\begin{array}{l}\text { Blood vessels } \\
\text { elongated in } \\
\text { direction of } \\
\text { strain }\end{array}$ \\
\hline $\begin{array}{l}\text { Piekarsky \& } \\
\text { Cohen }(1962)^{[2]}\end{array}$ & $?$ & $24 \mathrm{~h}$ & Ischemia & - \\
\hline Azuma $(1970)^{[6]}$ & $1.4-2.0$ & $\begin{array}{r}4 \mathrm{~h} \\
24 \mathrm{~h}\end{array}$ & $\begin{array}{l}\text { Capillaries obliterating } \\
\text { Capillaries disappeared }\end{array}$ & - \\
\hline \multirow[t]{5}{*}{ Rygh $(1972)^{[1]}$} & $0.05-0.1$ & $30 \mathrm{~min}$ & $\begin{array}{l}\text { Stasis ( } \pm \text { packing of eryth- } \\
\text { rocytes) }\end{array}$ & - \\
\hline & & $2 \mathrm{~h}$ & $\begin{array}{l}\text { Arterioles / capillaries } \\
\text { dilated }\end{array}$ & - \\
\hline & & 1-7 days & $\begin{array}{l}\text { Disintegration of blood ves- } \\
\text { sels }\end{array}$ & - \\
\hline & & $7-28$ days & $\begin{array}{l}\text { Regeneration of blood ves- } \\
\text { sels }\end{array}$ & - \\
\hline & 0.25 & $\begin{array}{l}30 \text { min } \\
28 \text { days }\end{array}$ & $\begin{array}{l}\text { More extensive changes } \\
\text { Hemorrhage }\end{array}$ & - \\
\hline Rygh $(1976)^{[12]}$ & 0.05 & 2 days & - & Dilated \\
\hline \multirow[t]{2}{*}{$\begin{array}{l}\text { Lindskog \& Lilja } \\
(1984)^{[14]}\end{array}$} & $0.2-0.4$ & $3 \mathrm{~h}$ & $\begin{array}{l}\text { Extravas a ted blood } \\
\text { (degenerated erythrocytes, } \\
\text { echinocytes, platelets) }\end{array}$ & - \\
\hline & & $24 \mathrm{~h}$ & $\begin{array}{l}\text { Disintegration of blood ves- } \\
\text { sels }\end{array}$ & - \\
\hline
\end{tabular}

on the vascular changes in pressure zones, few studies have focused on such changes in tension zones. As the ultrastructural vascular changes in the tension zone appear to have been neglected, the present study was conducted to document the qualitative changes in the tension zone of the PDL microvasculature after a short-term orthodontic extrusive force.

\section{Materials and Methods}

Six male Porton rats, aged 12 weeks and weighing 300-320 g each, were anesthetized with intraperitoneal urethane at a dosage of $30 \mathrm{mg} / 10 \mathrm{~g}$ body weight. An appliance designed to exert a continuous extrusive force on the molar was then fitted. The appliance (Fig. 1) consisted of 2 main parts-modified "rat-toothed" tweezers ( $T$ ) for attachment to the first molar and the appliance proper. A quick-release system (R1) permitted rapid and rigid attachment to the experimental tooth. A second quick-release system (R2) permitted ready fixation of the tweezers to the main appliance. By adjusting a modified micrometer screw gauge (M), the force applied could be varied and read from a pre-calibrated scale (S) via a deflection indicator (D). 
As soon as the rat was anesthetized, the beak of the tweezers was carefully attached to the buccal and lingual aspects of the right (experimental) maxillary first molar just above the free gingival margin. Once the tweezers had been firmly affixed to the tooth by locking R1, the tweezers were attached to the main appliance by securing R2. A ligature was used to secure the cranio-maxillary complex to the appliance base with the dorsal surface of the animal against the appliance base. The micrometer screw gauge was then adjusted to deliver a continuous extrusive force of $1-\mathrm{N}$ for $30 \mathrm{~min}$. The contralateral left first molar served as a control in all animals.

After $30 \mathrm{~min}$ of force application, each animal was perfused through the left ventricle with a solution of $4 \%$ glutaraldethyde and $0.89 \% \mathrm{OsO}_{4}$ in $0.1 \mathrm{M}$ cacodylate buffer at $\mathrm{pH}$ 7.4. The maxilla from each animal was then removed, hemisectioned and demineralized at $4^{\circ} \mathrm{C}$ with $0.1 \mathrm{M}$ EDTA in $2.5 \%$ cacodylate buffer, $\mathrm{pH}$ 6.4. When radiographic examination indicated the completion of demineralization, each maxillary portion was divided mid-sagittally through the mesial root to provide complete occlusal-apical blocks of both the control and experimental periodontal ligaments of the first molars. The blocks were post-fixed for one hour with $4 \% \mathrm{OsO}_{4}$ in cacodylate buffer and processed through an ethanol and propylene oxide series for embedding in Araldite.

For each animal, ten ultrathin sections (each $70 \mathrm{~nm}$ thick) of a defined apical PDL area in both the control and experimental ligaments were cut with a diamond knife, transferred to 200-mesh copper grids, and stained with modified Reynold's lead citrate for viewing and photography with a JOEL 100-S transmission electron microscope. Magnification accuracy was checked against a cross-grating replica.

Vessels were identified according to strict criteria ${ }^{[14]}$ and the numbers of vessels showing evidence of microvascular degeneration in the control and experimental sides were counted. The results were subjected to a 1-sample Student's $t$ test.

\section{Results}

In some of the venous vessels in the experimental PDL, it was noted that various parts of the endothelial wall were undergoing degeneration. In the affected areas, the endothelial cells became swollen and vacant (Fig. 2). The cytoplasm of the endothelial cells in the affected zone contained abnormally large, thin-walled vacuoles (Fig. 3). In other cells, the luminal plasmalemmal membrane had disintegrated, forming plasmalemmal tags (Fig. 2) projecting into the lumen, releasing their empty and vacuolar contents into the lumen.

In the nucleus, an increase in the width of the perinuclear space (Fig. 4), due to incipient shrinkage of the nucleus, was noted. The above-mentioned perinuclear space was characterized by a pale, "vacant" appearance (Figs. 4, 5).

The nucleus also appeared to have an increased number of notches and folds. No disruption of the adjacent basal lamina and pericytes was noted. Mitochondria and Golgi complexes appeared normal, whereas the endoplasmic reticulum was slightly distended. Intercellular junctions showed no increase in the width of the intercellular gaps. 
Not all the vessels in the experimental PDL exhibited the same degree of degeneration; some vessel types appeared to be affected more severely than others (Table 2). These changes were observed in $31 \%$ of the postcapillary venules and $18 \%$ of the venous capillaries while the thicker-walled arterial elements appeared to be spared. Similar degenerative changes in vessles were observed in less than $2 \%$ of the microvessels in the control PDL (Table 2).

Table 2 Statistical analysis of percentage of vessels with evidence of microvascular disintegration in control and experimental PDL

\begin{tabular}{|l|c|c|c|}
\hline & $\begin{array}{c}\text { Experimental } \\
(\mathrm{x} \pm \text { S.D. })\end{array}$ & $\begin{array}{c}\text { Control } \\
(\mathrm{x} \pm \text { S.D. })\end{array}$ & $t$ value \\
\hline Terminal arteriole & $0.24 \pm 0.20$ & $0.23 \pm 0.22$ & $0.4(\mathrm{NS})$ \\
\hline Arterial capillary & $0.19 \pm 0.18$ & $0.20 \pm 0.19$ & $-0.3(\mathrm{NS})$ \\
\hline Venous capillary & $18.15 \pm 2.36$ & $0.26 \pm 0.19$ & $20.9^{* *}$ \\
\hline Postcapillary venule & $31.20 \pm 3.61$ & $1.48 \pm 1.24$ & $29.3^{* *}$ \\
\hline $\begin{array}{l}\text { NS }: \text { Not significant } \\
{ }^{* *}: \mathrm{p}<0.01\end{array}$
\end{tabular}

\section{Discussion}

A 1-N force was used in this study, since comparable forces have been used by other authors to study orthodontic tooth movements in rat molars ${ }^{[6,7,15]}$. In the present study, the endothelial cells in some of the venous vessels of the experimental PDL often had large, empty spaces devoid of any identifiable content. Incipient shrinkage of several nuclei was also noted in the venous-type vessels of the experimental PDL. Interestingly, these degenerative changes were not observed in the arterial segments of the PDL microvascular bed. RYGH, studying changes in the tension zones of the rat molar PDL upon application of a $0.05-0.2-\mathrm{N}$ force over periods varying from $30 \mathrm{~min}$ to 28 days, did not observe any obvious changes in the endothelial cells or nuclei ${ }^{[12]}$. This variation could have been a reflection of the lighter forces used in his study compared with the present study. It is possible that the 1-N force used in the present study could have "injured" the PDL and led to an inflammatory response. The greater vulnerability of the venous segments during an inflammatory reaction may be a reflection of their relative inability to undergo distension, the presence of more fenestrae in the venous vessels or a defective basement membrane on the venous side of the circulation ${ }^{[16]}$.

STALLARD has hypothesized that structural alterations taking place in the loaded PDL may be due to alterations in nutritional and functional status ${ }^{[17]}$. However, in the present study, physical trauma due to orthodontic forces could not be disregarded as a contributory factor responsible for microvascular changes occurring in the PDL. Some authors note that both tension and compression zones show circulatory alterations ${ }^{[3]}$. It is therefore interesting to postulate that the PDL might respond to masticatory forces (i.e. intermittent loading) by subtle, yet reversible, physiologic vascular changes. However, if these forces are continuous in nature, then degenerative changes may occur in the more vulnerable venous segments of the vascular system. 


\section{Conclusion}

Degenerative changes in the endothelial cell wall and nucleus were observed in about $20-30 \%$ of venous-type vessels. However, the arterial vessels were generally spared. In the affected venous vessels, endothelial cells became swollen with the formation of abnormally large, thin-walled vacuoles. In a few of these endothelial cells, the luminal plasmalemmal membranes disintegrated, releasing their "empty" and "vacuolar" contents into the lumen. Incipient nuclear shrinkage resulting in the clear zone adjacent to several endothelial nuclei was also noted. Although such degenerative changes have been demonstrated in pressure zones of rats $^{[1]}$, vascular degeneration has not been described previously in tension zones. These early vascular changes noted in the present study support the findings of other authors ${ }^{[11]}$, who have implicated the vascular system as a "main mediator" in PDL remodelling associated with tooth movement.

\section{Acknowledgements}

The typing assistance of Mdm B. L. EK and photographic expertise of Mr. B. Joseph are gratefully acknowledged.

\section{References}

[1] RYGH, P.: Ultrastructural vascular changes in pressure zones of rat molar periodontium incident to orthodontic movement, Scand. J. Dent. Res., 80, 307-321, 1972

[2] Piekarsky, J. and Cohen, W.: Vascular changes in the periodontal ligament in experimental movement of the rat molar, Int. Ass. Dent. Res. Meeting, Abstract No. 252, p. 67, 1962

[3] Gaengler, P. and Merte, K.: Effects of force application on periodontal blood circulation. A vital microscopic study in rats, J. Periodont. Res., 18, 86-92, 1983

[4] Castelli, W. A. and Dempster, N. T.: The periodontal vasculature and its response to experimental pressures, J. Am. Dent. Assoc., 70, 890-905, 1965

[5] Macapanpan, L. C., Weinmann, J. P. and Brodie, A. G.: Early tissue changes following tooth movements in rats, Angle Orthod., 24, 79-95, 1954

[6] Azuma, M.: Study on histologic changes of periodontal membrane incident to tooth movement, Bull. Tokyo Med. Dental Univ., 17, 149-178, 1970

[7] Gianelly, A. A.: Force-induced changes in the vascularity of the periodontal ligament, Am. J. Orthod., 55, 5-11, 1969

[8] Buck, D. L. and Church, D. H.: A histological study of tooth movement, Am. J. Orthod., 62, 507-516, 1972

[9] RYGH, P. and ReItaN, K.: Ultrastructural changes in the periodontal ligament incident to orthodontic movement, Trans. Eur. Orthod. Soc., 393-405

[10] K Kouw, F. E. and Goldhaber, P.: Changes in vasculature of the periodontium associated with tooth movement in the rhesus monkey and dog, Archs. Oral Biol., 15, 1125-1132, 1970

[11] RyGH, P., Bowling, K., Hovlandsdal, L. and Williams, S.: Activation of the vascular system: a main mediator of periodontal fibre remodelling in orthodontic tooth movement, Am. J. Orthod., 89, 453-468, 1986

[12] RYGH, P.: Ultrastructural changes in tension zones of rat molar periodontium incident to orthodontic tooth movement, Am. J. Orthod., 79, 269-281, 1976

[13] Kuftinec, M. M.: Vascular changes due to the application of force to molar teeth in hamsters, J. Dent. Res., 47, 916-918, 1968

[14] LEw, K. K. K.: The periodontal microvasculature-a morphological and morphometric study, J. Nihon Univ. Sch. Dent., 29, 262-269, 1987

[15] BoNDEvIK, O.: Tissue changes in the rat molar periodontium following application of 
intrusive forces, Eur. J. Orthod., 2, 41-49, 1980

[16] Zweifach, B. W.: Microvascular aspects of tissue injury. In The Inflammatory Process, Zweifach, B. W., Grant, L. and McCluskey, R. T., Eds., 2nd edition, Volume II, 3-46, Academic Press, New York-London, 1973

[17] Stallard, R.: Alterations in cellular dynamics within the periodontium as a result of compressive forces. In The Mechanism of Tooth Support, Anderson, D. J., EAstoe, J. E., Melcher, A. H. and Picton, D. C. A., Eds, 136-139, John Wright \& Sons, Bristol, 1967 


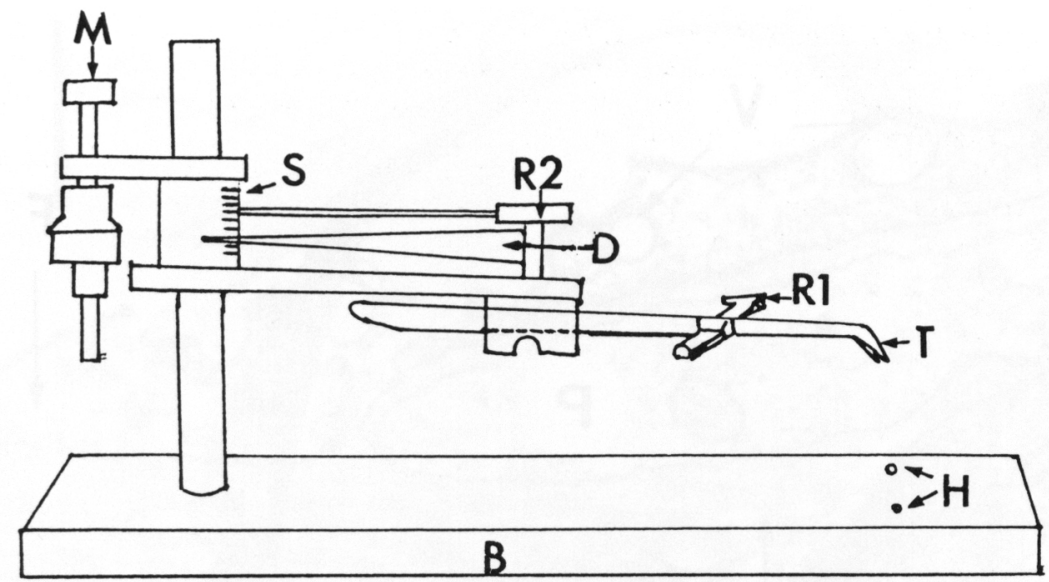

Fig. 1 The extrusion appliance. M, micrometer screw gauge. S, deflection scale. D, deflection indicator. R1, quick-release lever "1". R2, quick-release lever "2". T, tweezers. H, holes for passage of ligature to secure maxilla to appliance base. B, appliance base.

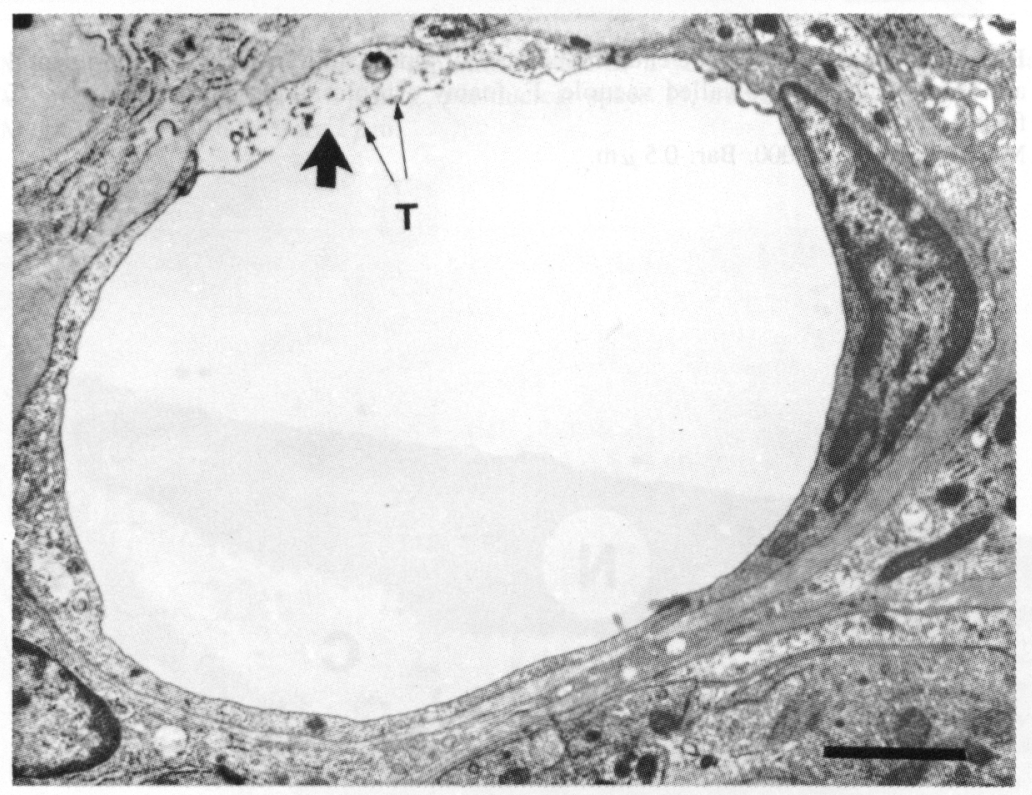

Fig. 2 Endothelial wall of a venous capillary showing disruption of the luminal plasma membrane (experimental PDL). Note the "vacant" appearance of the cytoplasm (arrowed). T, plasmalemmal tags.

Vessel luminal diameter: $84 \mu \mathrm{m}$. Magnification: x8,500. Bar: $2 \mu \mathrm{m}$. 


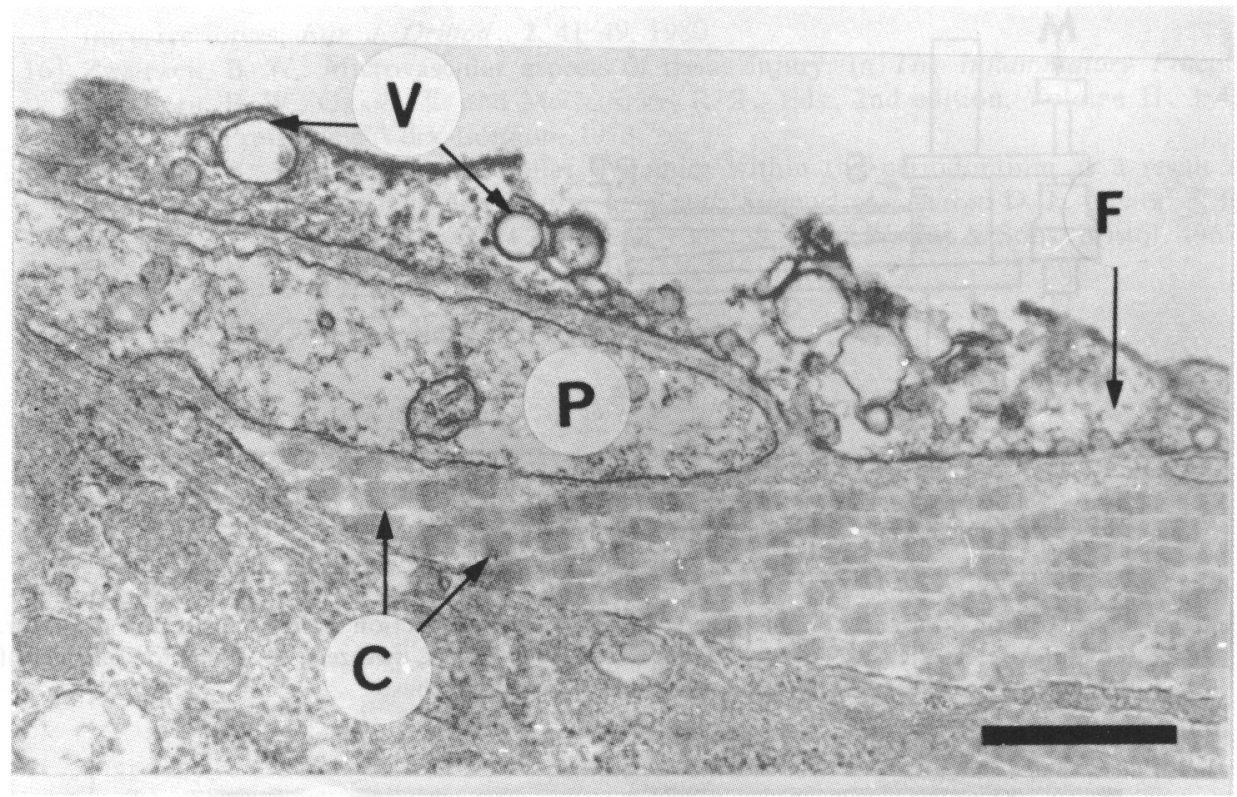

Fig. 3 Degeneration observed in the endothelial wall of a postcapillary venule (experimental PDL). V, abnormally large, thin-walled vacuole. F, foamy cytoplasm. P, pericytic process. C, collagen fibers.

Magnification: $\times 25,000$. Bar: $0.5 \mu \mathrm{m}$.

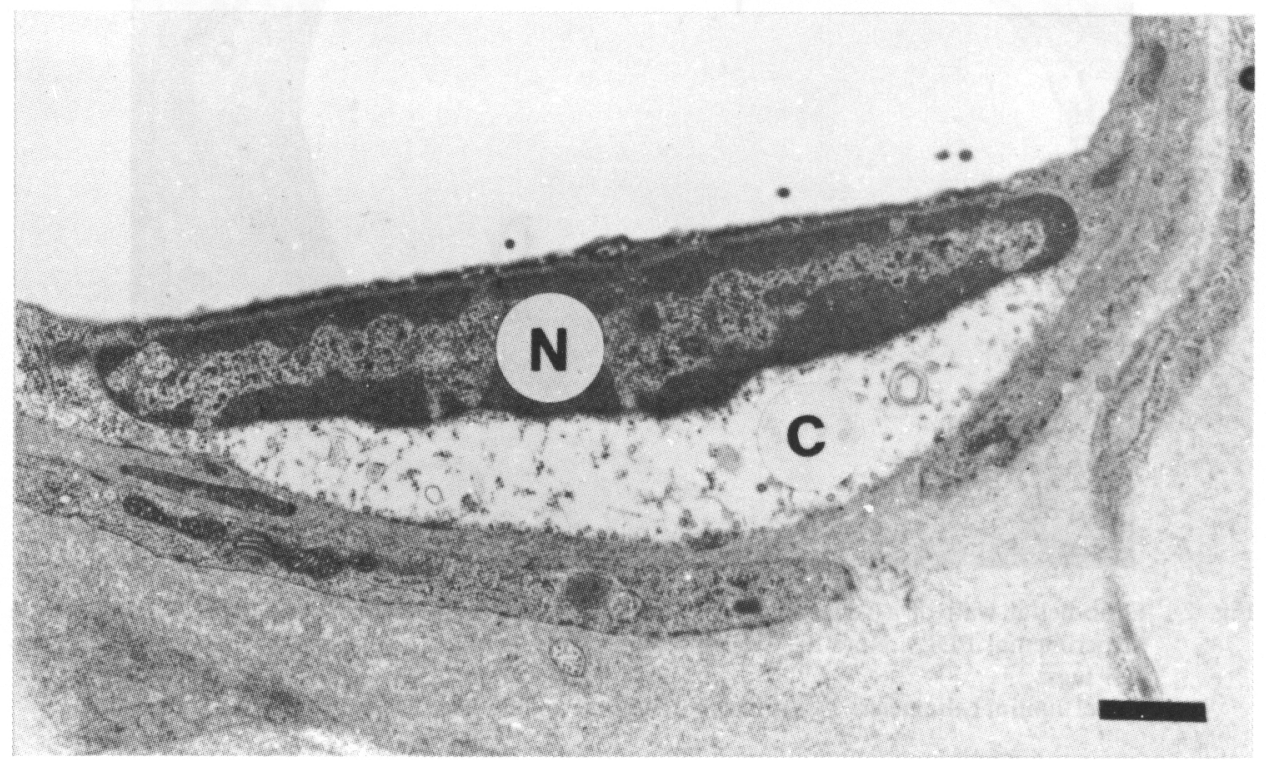

Fig. 4 Nuclear changes in a postcapillary venule (experimental PDL). Note the initial increase in the perinuclear space and its clear vacant-looking appearance (C). N, nucleus. Magnification: $\mathrm{x} 8,000$. Bar: $1 \mu \mathrm{m}$. 


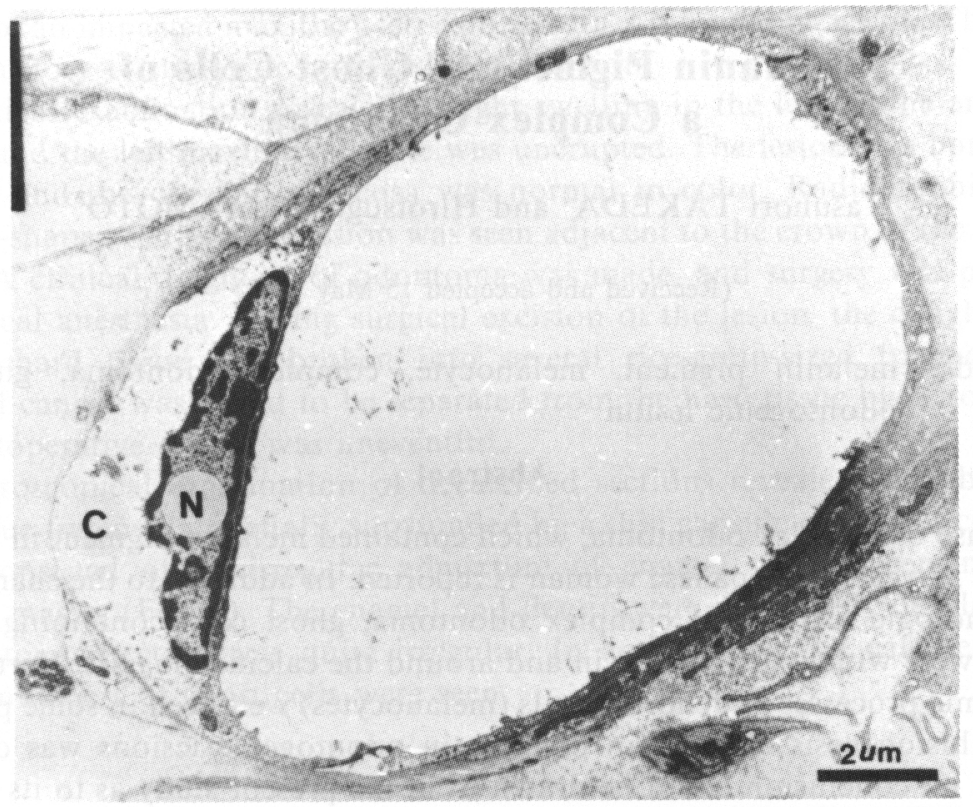

Fig. 5 More advanced stage of nuclear separation seen in a venous capillary (experimental PDL). Vessel luminal diameter: $8.8 \mu \mathrm{m}$. C, perinuclear space. $\mathrm{N}$, nucleus.

Magnification: $x 7,600$. Bar: $2 \mu \mathrm{m}$. 